\title{
UNA NUEVA ESPECIE DE BURSERA (BURSERACEAE), ENDÉMICA DE LA CUENCA BAJA DEL RÍO BALSAS EN LOS ESTADOS DE MICHOACÁN Y GUERRERO, MÉXICO *
}

\author{
FERnANdo Guevara-FÉFer \\ Universidad Michoacana de San Nicolás de Hidalgo, \\ Laboratorio de Sinecología, Morelia, Michoacán, México. \\ guevarafefer@yahoo.com.mx
}

\section{RESUMEN}

Se describe e ilustra una nueva especie de Burseraceae. Bursera xolocotzii es un árbol del bosque tropical caducifolio, conocido sólo de los alrededores de la presa de Infiernillo en los estados de Michoacán y Guerrero. La especie forma parte de la sección Bursera, destaca por sus hojas unifolioladas glabras, el aroma fuerte y persistente de la resina de las hojas y ramillas jóvenes, sus flores femeninas trímeras a tetrámeras, las masculinas tetrámeras a trímeras excepcionalmente pentámeras y el carácter de su corteza gris, lisa, no exfoliante. Presenta similitudes con Bursera laurihuertae Rzed. \& Calderón y con B. lunanii (Spreng.) C. D. Adams \& Dandy ex Proctor.

Palabras clave: Bursera, Burseraceae, Guerrero, México, Michoacán, taxonomía.

\begin{abstract}
A new species of Burseraceae is described and illustrated. Bursera xolocotzii is a tropical deciduous forest tree restricted to the surroundings of Infiernillo region (Michoacán and Guerrero states). This species is part of the section Bursera, remarkable for its glabrous
\end{abstract}

\footnotetext{
* Trabajo realizado parcialmente con el apoyo económico de la Coordinación de la Investigación Científica de la Universidad Michoacana de San Nicolás de Hidalgo.
} 
leaves, a strong and persistent smell of its young leaves and branchlets, its trimerous to tetramerous feminine flowers, and tetramerous to trimerous, rarely pentamerous masculine flowers, and its grey, smooth non exfoliating cortex. It presents similitudes with $B$. laurihuertae Rzed. \& Calderón and with B. lunanii (Spreng.) C. D. Adams \& Dandy ex Proctor.

Key words: Bursera, Burseraceae, Michoacán, Guerrero, Mexico, taxonomy.

Bursera xolocotzii Guevara sp. nov. Fig. 1.

Arbor glabra 4-6 m alta dioecia; truncus cortice exteriore griseo laevi non exfolianti, ramuli juniores et folia foetidissima; folia simplicia (unifoliolata) obovata, 4.9-8.7 cm longa, apice rotundata et mucronulata rarissime emarginata, basi acuta usque rotundata, marginibus integra; inflorescentiae cymosae paniculiformes, pauciflorae 20-23 mm longae, flores masculini maximam partem tetrameri interdum trimeri rarissime pentameri, flores feminei maximam partem trimeri rarisime tetrameri, calycis lobi triangulares ca. $1 \mathrm{~mm}$ longi et lati virides, petala oblanceolato - oblonga cucullata 3-4 mm longa viridia, ovarium tricarpellare, triloculare maximam partem, rarissime tetracarpellare, tetraloculare; drupae trivalvatae, rarissime tetravalvatae oblique subsphaericae ad globoso-pyramidales (obovoideae) 4-6.2 mm longae, pyrenae oblique obovoideae 4-4.6 $\mathrm{mm}$ longae et 3.5-4.3 $\mathrm{mm}$ latae, pseudoarillo rubro-roseo omnino indutae.

Árbol caducifolio dioico, de 4 a $7 \mathrm{~m}$ de alto, copa irregular, corteza lisa, la externa delgada, de color gris claro, no exfoliante, la segunda capa de color verde claro, la más íntima de color rojo obscuro, con látex blanquecino, la resina transparente, de aroma suave; las ramillas terminales colgantes, glabras, con abundante resina de aroma desagradable, fuerte y penetrante, incluso a distancia; hojas unifolioladas, alternas, dispuestas a lo largo de las ramillas tanto terminales como laterales, de 4.9 a $8.7 \mathrm{~cm}$ de largo, lámina de los folíolos obovada, ápice redondeado, inconspicuamente mucronulado, rara vez emarginado, margen entero, ocasionalmente ondulado, base aguda a redondeada y a menudo ligeramente oblicua, de color verde claro, algo brillante, de textura membranácea y con las nervaduras conspicuas en ambas superficies, lámina de (4.2)5 a 6(7.4) cm de largo y de (2) 2.5 a 3.1(3.5) cm de ancho, pecíolo de (0.8)0.9 a 1.1(1.5) cm de largo, ligeramente ensanchado hacia la base, acanalado en su cara superior; todas las partes foliares 
Guevara-Féfer: Nueva especie de Bursera endémica de la cuenca baja del río Balsas
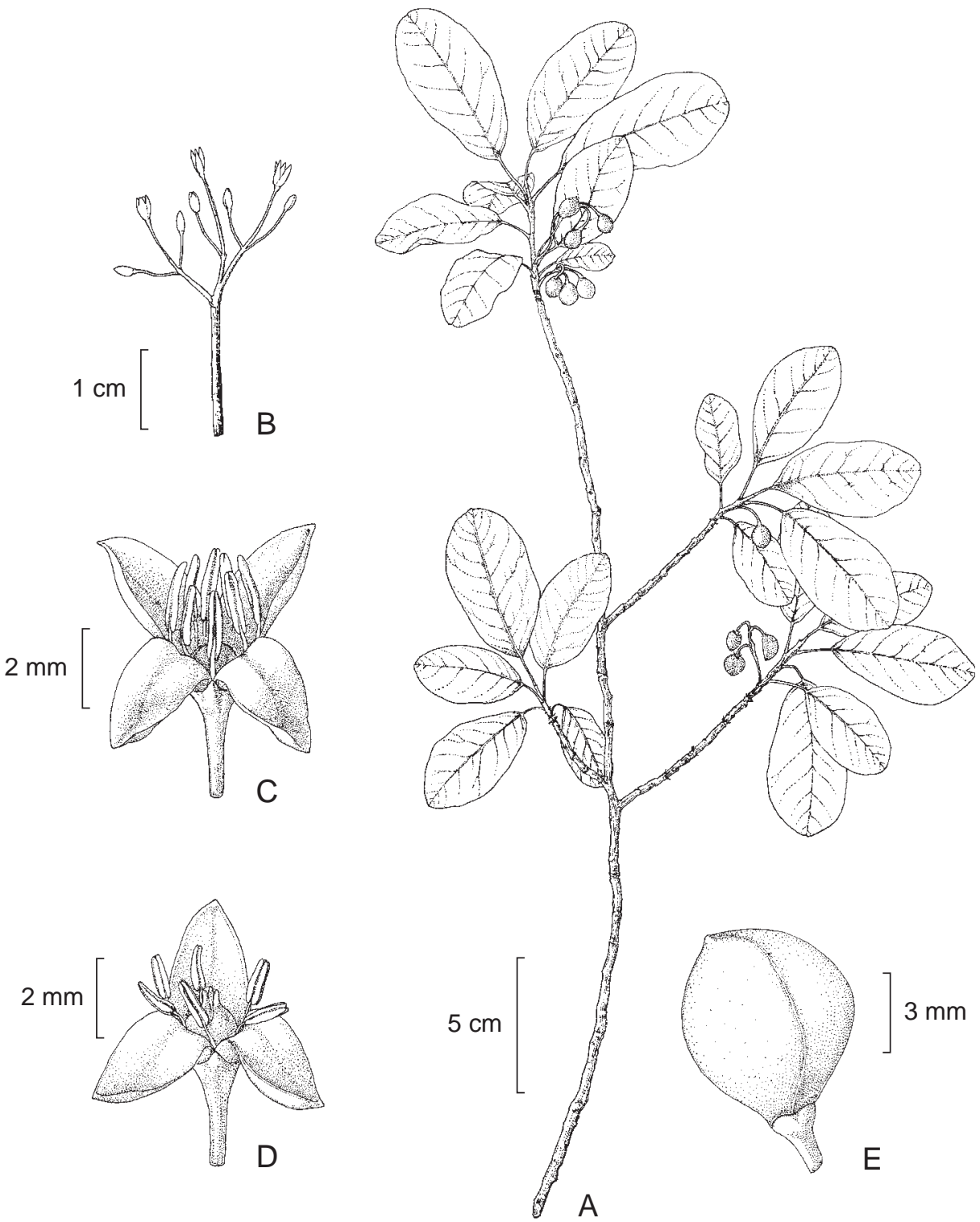

Fig. 1. Bursera xolocotzii Guevara-Féfer. A. rama con hojas y frutos; B. inflorescencia; C. flor masculina tetrámera; D. flor femenina trímera; E. fruto. Ilustrado por Rodrigo Tavera Mendoza. 
glabras; inflorescencias en cimas paniculiformes de 20 a $23 \mathrm{~mm}$ de largo con (1)3 a 4(6) flores, las femeninas más pequeñas que las masculinas, dispuestas hacia la parte inferior de la ramilla terminal en pequeños grupos o solitarias en las axilas de las hojas tiernas, pedúnculo de 6 a $11 \mathrm{~mm}$ de largo, aplanado y estriado en su cara interior, con diminutas glándulas sésiles, escasas y esparcidas, raquis de apariencia similar; brácteas de 0.8 a $1 \mathrm{~mm}$ de largo y de 0.5 a $0.8 \mathrm{~mm}$ de ancho, triangulares, con el ápice agudo, la superficie externa cubierta de diminutas glándulas sésiles, la interna glabra; las bracteolas similares a las brácteas, de 0.25 a $0.5 \mathrm{~mm}$ de largo $\mathrm{y} \pm 0.25 \mathrm{~mm}$ de ancho; pedicelos de las flores de 4 a $6 \mathrm{~mm}$ de largo, glabros; flores masculinas predominantemente tetrámeras con menos frecuencia trímeras, excepcionalmente pentámeras, sépalos triangulares, de color verde claro, el ápice agudo, la superficie externa con glándulas diminutas sésiles concentradas en el borde y el ápice, la interna glabra, unidos en la base, de 0.5 a $1 \mathrm{~mm}$ de largo y de 0.5 a $1 \mathrm{~mm}$ de ancho, subiguales, pétalos libres entre sí, oblanceolados a oblongos u ovados, reflejos, de color verde claro, ápice cortamente apiculado, superficie externa con glándulas sésiles diminutas, de color claro, esparcidas y concentradas en el ápice, dispersas y escasas hacia la base; la superficie interna glabra, de 3.2 a $4 \mathrm{~mm}$ de largo y 1.5 a $2 \mathrm{~mm}$ de ancho, subiguales, estambres 6,8 o 10, libres, en dos series subiguales, de 3 a $3.5 \mathrm{~mm}$ de largo, anteras oblongas, de $1.5 \mathrm{a} 2 \mathrm{~mm}$ de largo y de 0.3 a $0.5 \mathrm{~mm}$ de ancho, filamentos de 1.5 a $2 \mathrm{~mm}$ de largo, ligeramente ensanchados hacia la base e insertos entre 0.25 y $0.5 \mathrm{~mm}$ de la base de las anteras, con glándulas diminutas dispersas, gineceo vestigial de menos de $0.5 \mathrm{~mm}$ de largo, el disco provisto de lóbulos dobles en cantidad igual a la de sépalos o pétalos, cubiertos de papilas cortas, de forma semejante a una copa; flores femeninas predominantemente trímeras, menos comúnmente tetrámeras, de forma, color, textura y pubescencia semejantes a las masculinas, sépalos de $\pm 1 \mathrm{~mm}$ de largo y $\pm 1 \mathrm{~mm}$ de ancho, subiguales, pétalos, de 3 a $4 \mathrm{~mm}$ de largo y de 1.5 a $2 \mathrm{~mm}$ de ancho, subiguales, estaminodios 6 a 8 , libres, en dos series, subiguales, de 1 a $3 \mathrm{~mm}$ de largo; anteras de 0.3 a $0.5 \mathrm{~mm}$ de largo y 0.25 a $0.5 \mathrm{~mm}$ de ancho, filamentos ligeramente ensanchados hacia la base con escasos pelos cortos, blancos, esparcidos, de 0.2 a $0.5 \mathrm{~mm}$ de largo, insertos entre 0.25 a $0.5 \mathrm{~mm}$ de la base de la antera, ovario tricarpelar, trilocular o excepcionalmente tetralocular, con dos óvulos por cavidad, glabro, estilo simple glabro, estigma cortamente trilobado o tetralobulado, papiloso, disco provisto de lóbulos dobles en cantidad igual a la de los sépalos o pétalos, papilado; infrutescencias de (13) 15 a $22 \mathrm{~mm}$ de largo con pocos frutos (1 a 4), pedúnculos de (5)6 a 10(15) $\mathrm{mm}$ de largo, pedicelos del fruto de 4 a $6 \mathrm{~mm}$ de largo; drupas trivalvadas, rara vez tetravalvadas, orbiculares a obovoides, de (4)5 a 6(6.2) $\mathrm{mm}$ de 
largo y de (4)5 a 6( 6.7) mm de ancho, valvas subiguales, dos de la misma forma y tamaño, ligeramente cóncavas, la tercera casi del doble de ancho de las otras, plana en su parte superior y marcadamente cóncava hacia la base, pseudoarilo de color rojo-rosado, cubriendo totalmente el endocarpio que es de color claro y mide de 4 a $4.6 \mathrm{~mm}$ de largo y de $3.5 \mathrm{a} 4.3 \mathrm{~mm}$ de ancho, con dos caras iguales y ligeramente redondeadas, la otra casi del doble de ancho de las demás, aplanada en su parte superior y conspicuamente redondeada, todas las partes de la infrutescencia (pedúnculo, raquis, pedicelo y valvas) glabras.

Tipo: MÉXICO, Michoacán: municipio de Arteaga, El Machute, alrededo-

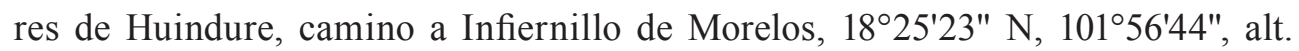
$315 \mathrm{~m}$, bosque tropical caducifolio sobre ladera de mediana a fuerte pendiente, 4.VII.2008, árbol femenino $7 \mathrm{~m}$, corteza lisa, gris, no exfoliante, ramillas y hojas de olor desagradable fuerte, Fernando Guevara Féfer, Rossana Gil Medina y Carlos Sosa Ramírez 14758 (Holotipo en IEB, isotipos por distribuirse a EBUM, ENCB y MEXU).

Material adicional examinado: Michoacán: municipio de Arteaga. El Machute, $30 \mathrm{~km}$ al NW de Infiernillo, cerca del Ejido Huindure, alt. $400 \mathrm{~m}$, bosque tropical caducifolio con cactos arborescentes, sobre ladera de roca metamórfica, de mediana a fuerte pendiente, suelos someros y pedregosos, 21.VIII.1979, árbol femenino 4 a $6 \mathrm{~m}$ de alto, corteza lisa gris, no exfoliante, ramillas y hojas de olor desagradable fuerte y penetrante, Fernando Guevara Féfer, Luis Ortiz Arias, Jorge Díaz de La Cruz y Rodolfo Sánchez Benítez 795 (EBUM, ENCB, IEB, MEXU); ibid., 5.VI.1980, árbol masculino, Fernando Guevara Féfer y Sergio Zamudio Ruiz 1055, 1062, 1080 (EBUM, ENCB, IEB, MEXU); ibid., 27.VI.1980, árbol masculino, Fernando Guevara Féfer y Luis Ortiz Arias 1251, 1253, 1255 (EBUM, ENCB, IEB, MEXU); 1 km al W de Huindure, rumbo a Cuatro Caminos, alt. 350 m, 27.VI.1980, árbol masculino 6 m, Fernando Guevara Féfer y Luis Ortiz Arias 1057 (EBUM, ENCB, IEB, MEXU); El Machute, cerca del ejido Hindure, $30 \mathrm{~km}$ al NNW de Infiernillo, sobre la carretera a Nueva Italia, alt. $350 \mathrm{~m}$, ladera de roca metamórfica con vegetación de bosque tropical caducifolio, árbol femenino, 17.VIII.1980. Jerzy Rzedowski 36879 (ENCB). Guerrero: municipio Coahuayutla; $14 \mathrm{~km}$ al S de la cortina de la Presa de Infiernillo, rumbo a Coahuayutla, alt. 220 m, árbol masculino de 6-7 m, corteza grisácea, no exfoliante, ramillas y hojas de olor fuerte y penetrante, 25.VIII.1979, Fernando Guevara Féfer, Luis Ortiz Arias, Jorge Díaz de la Cruz y Rodolfo Sánchez Benítez 814 (EBUM, ENCB, IEB, MEXU). 
La nueva especie sólo se conoce de las localidades mencionadas, en la región aledaña a la presa de Infiernillo, hacia la zona de menor altitud de la cuenca baja del río Balsas, crece en lomeríos de pendiente mediana a fuerte, en la condición más xérica del bosque tropical caducifolio con cactáceas arborescentes, sobre suelos someros y pedregosos; asociada con Euphorbia schlechtendalii Boiss., Bursera sarukhanii Guevara \& Rzed., Bursera crenata Paul. G. Wilson, B. trimera Bullock, Plumeria rubra L., Haematoxylon brasiletto H. Karst. y Poeppigia procera C. Presl.

Florece de principios de mayo a principios de junio y desprende sus hojas a finales del año.

Considerando las características que McVaugh y Rzedowski (1965) y Rzedowski y Kruse (1979) han sugerido para separar a las dos secciones en que se subdivide el género y a pesar del carácter no exfoliante (que es constante en los individuos observados), Bursera xolocotzii se puede ubicar en la sección Bursera. Es pertinente remarcar, como lo hicieron Guevara-Féfer y Rzedowski (1981), que el carácter no exfoliante de la corteza externa, si bien constante en casi todos los miembros de la sección Bullockia (excepto por ejemplo en B. sarcopoda Paul G. Wilson y B. mirandae Toledo) no es exclusivo de la misma y no resulta un rasgo determinante en la separación y diferenciación de las dos secciones del género Bursera, lo cual tampoco es válido en la diferenciación genérica entre Bursera y Commiphora, ya que en este último existen especies con corteza tanto exfoliante como no exfoliante.

Con relación al número de partes florales, McVaugh y Rzedowski (1965), indicaron que "The flowers in the bivalvate group of species are predominatly 4-merous (occasionally 5-merous); in the trivalvate group they may be 3-4 or 5 merous". Posteriormente Gillet (1980), sugirió que las flores femeninas en la sección Bursera son siempre trímeras y que usualmente las flores masculinas tienen un número diferente de partes florales con predominancia de pentamería sobre tri o tetramería y da a esta característica y otras, suficiente peso como para justificar las distinciones subgenéricas que hace de las dos secciones.

Es conveniente destacar el hecho de que el número de partes florales en $B$. xolocotzii presenta ciertas variaciones; así, las flores masculinas son predominantemente tetrámeras, aunque las hay trímeras y pentámeras incluso en una misma inflorescencia; mientras que las femeninas son predominantemente trímeras y con menos frecuencia tetrámeras. En tal virtud, el número de partes florales tampoco resulta un carácter determinante en la diferenciación de las dos secciones o subgéneros en los que ha sido dividido el género Bursera. 
Por lo que toca al número de carpelos, de 247 flores examinadas de Bursera xolocotzii, 24 son tetrámeras y de éstas seis presentan ovario tetracarpelar, tetralocular y tetralobulado. Una cierta variabilidad ha sido anotada también por Gillet (1980), tanto para el género Bursera como para Commiphora (este último esencialmente sudafricano, típicamente bicarpelar y relacionado íntimamente con el primero), dicho autor menciona un registro de 2 frutos triloculares y 1 tetralocular de un total de 56 de Commiphora wightii Arn., así como 22 frutos triloculares entre 320 de Commiphora stocksiana Engler (=Balsamodendrum pubescens Stocks). Para Commiphora leptophloeos (Mart.) Gillet, Engler (1883) describió el estigma como trilobado, pero recientemente se ha confirmado la presencia de estigmas bilobados y ovarios biloculares. Por lo anterior, resulta que tanto en el género Commiphora como en las dos secciones o subgéneros del género Bursera, existen ovarios bi- tri- y tetracarpelares.

Con respecto a las afinidades de B. xolocotzii, aunque no resultan del todo claras, en principio la planta parece tener similitud significativa con un grupo de especies del complejo Bursera simaruba que presentan hojas unifolioladas (ver Cuadro 1). De éstas, por otro lado, es distintiva por el olor penetrante y desagradable de la resina de las ramillas tiernas y hojas que persiste en los ejemplares de herbario aún después de varios años, sus flores femeninas trímeras a tetrámeras, las masculinas, tetrámeras a trímeras, excepcionalmente pentámeras y el carácter de su corteza gris, no exfoliante. También se distingue por su distribución tanto geográfica como ecológica; ya que al parecer es endémica de la parte más baja de la cuenca del Balsas hacia los límites de los estados de Michoacán y Guerrero, en áreas del bosque tropical caducifolio con cactáceas arborescentes en su condición más xérica, con relativamente escasa precipitación $(600 \mathrm{~mm})$ y temperaturas medias anuales cercanas a $\operatorname{los} 30^{\circ} \mathrm{C}$.

En el Cuadro 1 se comparan algunas características de Bursera xolocotzii y de las restantes especies de la sección Bursera registradas para México que presentan al menos algunas hojas unifolioladas, con el margen entero y la corteza roja exfoliante. Bursera krusei Rzed., B. instabilis McVaugh \& Rzed. y B. laurihuertae Rzed. \& Calderón forman parte del grupo "B. simaruba", mientras que B. schlechtendalii Engl. y B. chemapodicta Rzed. \& E. Ortiz fueron incluidas dentro del grupo " $B$. fagaroides", de acuerdo con el arreglo filogenético molecular de Becerra y Venable (1999) y Becerra (2003).

Con B. schlechtendalii comparte el carácter unifoliolado, la forma, borde y textura del foliolo pero difiere de la misma en el carácter no exfoliante de su corteza externa y en la presencia de frutos en racimos cortos y no solitarios o fasciculados. 
Acta Botanica Mexicana 92: 119-128 (2010)

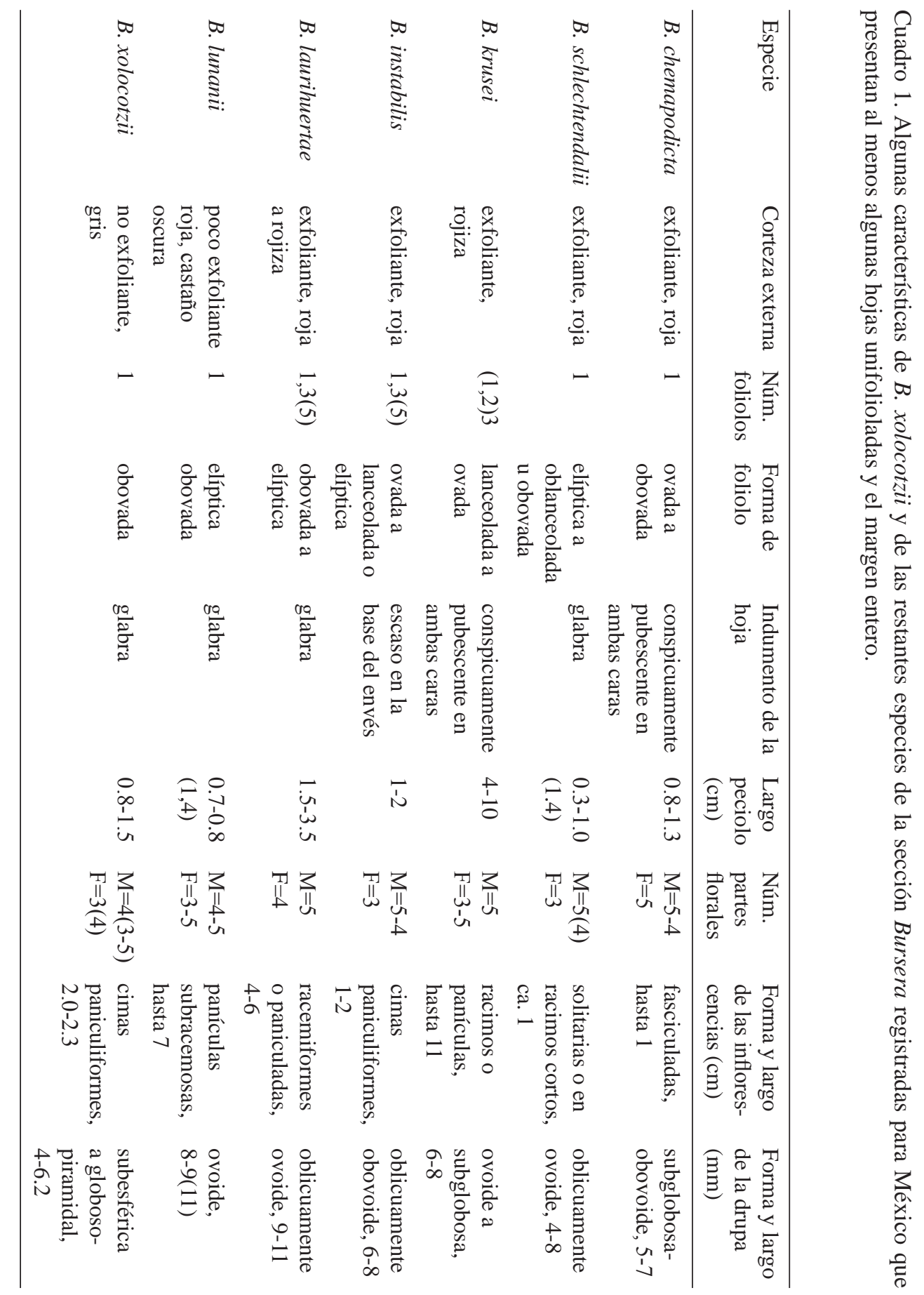


De B. chemapodicta se diferencia por el rasgo pubescente del foliolo y las flores, los frutos solitarios a fasciculados y la corteza exfoliante rojiza de esta especie. De $B$. instabilis y B. krusei difiere en la forma de los folíolos que son más grandes, acuminados y los pecíolos más largos, así como por el carácter exfoliante de la corteza roja en estas especies.

Las mayor similitud se presenta con Bursera laurihuertae Rzed. \& Calderón, una especie restringida al sureste del estado de Oaxaca, que desarrolla hojas unifolioladas y con mucha frecuencia también trifolioladas, hasta de 6(9) cm de largo y 5-4.5 cm de ancho, de consistencia cartácea a coriácea, las inflorescencias de 4 a 6 cm de largo, los frutos 9 a $11 \mathrm{~mm}$ de largo y la corteza externa rojiza exfoliante en tiras grandes y delgadas (Rzedowski y Calderón, 2000); a su vez B. xolocotzii desarrolla sólo hojas unifolioladas de consistencia membranácea, los foliolos, peciolos e inflorescencias de menor tamaño, los frutos miden 4 a $6.2 \mathrm{~mm}$ de largo y la corteza externa es de color gris y no es exfoliante.

Rzedowski y Calderón (2000) al analizar las posibles afinidades de B. laurihuertae comentan la existencia de algunas especies del archipiélago antillano (así como de Venezuela) que se han descrito con hojas uni a trifolioladas y de margen entero como B. lunanii (Spreng.) C. D. Adams \& Dandy ex Proctor. Esta planta fue registrada por Adams (1972) como endémica de la isla de Jamaica y descrita como un árbol hasta de $15 \mathrm{~m}$ de alto, corteza de color moreno castaño (obscura) poco exfoliante, presenta hojas unifolioladas escasamente discoloras, de consistencia cartácea a coriácea; sus flores se agrupan en panículas racemiformes más largas (hasta de 7 $\mathrm{cm}$ de largo), sus flores (al menos las masculinas) son muy pequeñas, de escasos 2 mm de longitud y tienen los lóbulos del cáliz de aproximadamente la mitad de largo de los pétalos, mientras que los frutos ovoides son más grandes que los de $B$. laurihuertae y B. xolocotzii. La época de floración de B. lunanii comprende de enero a abril, mientras que la de $B$. laurihuertae corresponde a los meses de marzo a abril y la de B. xolocotzii de finales de mayo a principios de junio.

Dichos autores plantean la posibilidad de que la similitud en la morfología foliar entre algunas de las especies que presentan al menos parcialmente hojas unifolioladas, puede obedecer a un proceso evolutivo de convergencia. La evidencia disponible sugiere que esta tendencia se ha presentado en varios complejos tanto en la sección Bursera como en Bullockia y se puede considerar al carácter unifoliolado como derivado (Rzedowski y Kruse, 1979).

Tomando en cuenta que la especie sólo se conoce de las localidades mencionadas, así como por el escaso número de individuos observados, se considera que se encuentra en peligro de extinción. 
El nombre de esta especie se dedica a la memoria del Ingeniero Efraím Hernández Xolocotzi, botánico mexicano, pionero y fundador de las bases teóricas y metodológicas de la investigación etnobotánica en México.

\section{AGRADECIMIENTOS}

El autor agradece a los doctores Jerzy Rzedowski R., Sergio Zamudio Ruiz y Emmanuel Pérez Calix, la revisión crítica y correcciones al manuscrito; a dos revisores anónimos que mejoraron el manuscrito. El autor forma parte del programa de postgrado en Ciencias Biológicas de la Universidad Nacional Autónoma de México. La ilustración es obra del maestro Rodrigo Tavera Mendoza.

\section{LITERATURA CITADA}

Adams, D. C. 1972. Burseraceae. In: Flowering plants of Jamaica. University of the West Indies. Mona. pp. 391-392.

Becerra, J. X. 2003. Evolution of Mexican Bursera (Burseraceae) inferred from ITS, ETS and 5S nuclear ribosomal DNA sequences. Molec. Phylog. Evol. 26: 300-309.

Becerra, J. X. y D. L. Venable. 1999. Nuclear ribosomal DNA phylogeny an its implications for evolutionary trends in Mexican Bursera (Burseraceae). Amer. Jour. Bot. 86: 10471057.

Engler, A. 1883. Burseraceae. DC. Monogr. Phaner. 4: 1-169.

Gillet, J. B. 1980. Commiphora (Burseraceae) in South America and its relationship to Bursera. Kew Bull. 34: 569-589.

Guevara-Féfer, F. y J. Rzedowski. 1981. Notas sobre el género Bursera (Burseraceae) en Michoacán. I. Tres especies nuevas de los alrededores de la presa del Infiernillo, con algunos datos relativos a la región. Bol. Soc. Bot. Méx. 39: 63-81.

McVaugh, R. y J. Rzedowski. 1965. Synopsis of the genus Bursera L. in western Mexico, with notes on the material of Bursera collected by Sessé \& Mociño. Kew Bull. 18: 317-382.

Rzedowski, J. y G. Calderón. 2000. Una nueva especie de Bursera (Burseraceae) del estado de Oaxaca (México). Acta Bot. Mex. 52: 75-81.

Rzedowski, J. y H. Kruse. 1979. Algunas tendencias evolutivas en Bursera (Burseraceae). Taxon 28: 102-116. 